\title{
A Case of Lynch Syndrome with the Deletion of Multiple Exons of the MLH1 Gene, Detected by Next-Generation Sequencing
}

Jinyoung Hong ${ }^{1}$, Hyunki Kim ${ }^{1}$, Yong Sang Hong ${ }^{2}$, Woochang Lee ${ }^{1}$, Seok-Byung Lim ${ }^{3}$, Jeong-Sik Byeon ${ }^{4}$, Sail Chun', and Won-Ki Min ${ }^{1}$ Departments of ${ }^{1}$ Laboratory Medicine, ${ }^{2}$ Oncology, ${ }^{3}$ Surgery, and ${ }^{4}$ Gastroenterology, Asan Medical Center, University of Ulsan College of Medicine, Seoul, Korea

Corresponding author: Woochang Lee Department of Laboratory Medicine, Asan Medical Center, University of Ulsan College of Medicine, 88 Olympic-ro 43-gil, Songpa-gu, Seoul 05505, Korea Tel: +82-2-3010-4506

Fax: +82-2-478-0884

E-mail: wlee1@amc.seoul.kr

pISSN: 2384-2458

eISSN: 2288-7261

\begin{abstract}
A 26-year-old man underwent colonoscopy to investigate weight loss and a lesion suspicious of colorectal cancer was detected. He had a family history of colorectal cancer and hepatocellular carcinoma. The biopsy result of the lesion showed a well-differentiated adenocarcinoma of the sigmoid colon and he underwent curative anterior resection of the colon. A microsatellite instability (MSI) test was performed on the resected tumor tissue specimen and it was found to be MSI-high. A next-generation sequencing (NGS)-based hereditary tumor panel test was performed on his peripheral blood to detect the causative germline variant. Neither a pathogenic variant nor a variant of uncertain significance was found in the single nucleotide variant (SNV) and small indel variant analyses. However, a copy number variation $(\mathrm{CNV})$ detection algorithm identified a variant compatible with the deletion of exon 7 to exon 19 of the MLH1 gene. This finding was confirmed to be a true deletion by multiplex ligation-dependent probe amplification. Therefore, the deletion of exon 7 to exon 19 of the MLH1 gene was regarded as the causative pathogenic genetic variant for his colorectal cancer and familial genetic testing was recommended. Therefore, patients with suspected cancer syndromes, including hereditary colorectal cancer, should be tested for germline mutations including CNVs, SNVs, and indels. NGS is a technique that can simultaneously detect SNVs and CNVs and therefore, it has clinical utility for genetic testing for hereditary diseases.
\end{abstract}

(Lab Med Qual Assur 2019;41:220-224)

Key Words: DNA copy number variation, $M L H 1$, Next-generation sequencing

Received October 18, 2019, Revision received November 7, 2019, Accepted November 9, 2019

\section{증례}

26세 남자 환자가 2 개월간 $14 \mathrm{~kg}$ 의 체중 감소가 있었으 며, 이에 대한 검사를 위해 시행한 대장내시경에서 항문피 부선 상부 $32 \mathrm{~cm}$ 부위에서 종양 의심소견이 보여 조직검사 를 시행하였고, 조직검사결과 고분화선암으로 밝혀졌다. 환 자의 가족력에서는 외할아버지와 아버지가 대장암, 할아버지 가 간암을 않은 이력이 있어, Bethesda guideline을 만족시
켜 Lynch syndrome이 의심되었다. 환자는 에스자결장암 진 단하에 결장과 직장의 전방절제술을 시행 받았으며, 절제된 조직의 병리검사결과 선암으로 진단되었다. 절제된 선암 조 직에서 microsatellite instability (MSI) 검사를 시행한 결과, BAT26, D5S346, BAT25, D2S123 마커에서 MSI 소견이 발 견되었으며, D17S250 마커에서는 loss of heterozygosity 소 견이 발견되었다. 따라서 환자의 MSI 검사결과는 마커 5개 중 4개 양성으로 MSI-high로 판정되었다. 선암 조직의 면역 


\section{LABORATORY MEDICINE and QUALITY ASSURANCE}

\section{Jinyoung Hong et al • A Case of MLH1 Exonic Deletion}

조직화학염색 결과 $\mathrm{MLH} 1$ 에 대해서는 음성이었고, MSH2에 대해서는 양성으로 나타났다. 이에 따라 DNA 복제실수교정 (mismatch repair, MMR) 유전자의 변이가 의심되어, 환자 의 말초혈액 검체를 이용하여 차세대 염기서열 분석법(next- generation sequencing, NGS)을 기반으로 한 유전성 종양 유전자 패널검사가 이루어졌다(Miseq Dx; Illumina, San Diego, CA, USA). 해당 NGS 패널은 Lynch syndrome의 원 인 유전자로 알려진 $M L H 1, M S H 2, M S H 6, P M S 2$ 를 포함
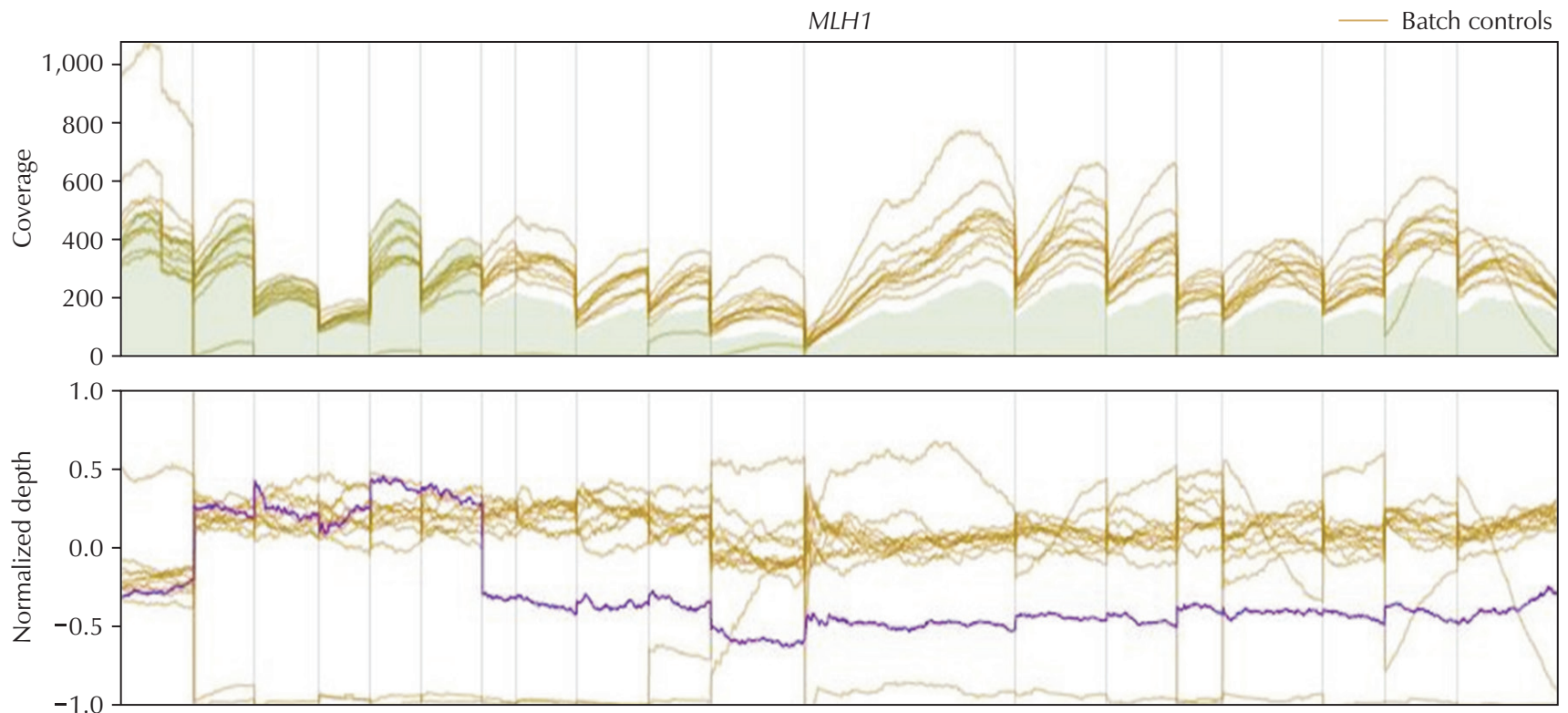

\begin{tabular}{|c|c|c|c|c|c|c|c|c|c|c|c|c|c|c|c|c|c|c|c|}
\hline NM_000249 & 1 & 2 & 3 & 4 & 5 & 6 & 7 & 8 & 9 & 10 & 11 & 12 & 13 & 14 & 15 & 16 & 17 & 18 & 19 \\
\hline NM_001167617 & & & & 4 & 5 & 6 & 7 & 8 & 9 & 10 & 11 & 12 & 13 & 14 & 15 & 16 & 17 & 18 & 19 \\
\hline NM_001167618 & & & & & & & & & 9 & 10 & 11 & 12 & 13 & 14 & 15 & 16 & 17 & 18 & 19 \\
\hline VM_001167619 & & & & & & & & & 8 & 9 & 10 & 11 & 12 & 13 & 14 & 15 & 16 & 17 & 18 \\
\hline NM_001258271 & 1 & 2 & 3 & 4 & 5 & 6 & 7 & 8 & 9 & 10 & 11 & 12 & 13 & 14 & 15 & 16 & & & 17 \\
\hline NM_001258273 & & & & & & & & & 8 & 9 & 10 & 11 & 12 & 13 & 14 & 15 & 16 & 17 & 18 \\
\hline JM_001258274 & & & & & & & & & 10 & 11 & 12 & 13 & 14 & 15 & 16 & 17 & 18 & 19 & 20 \\
\hline
\end{tabular}

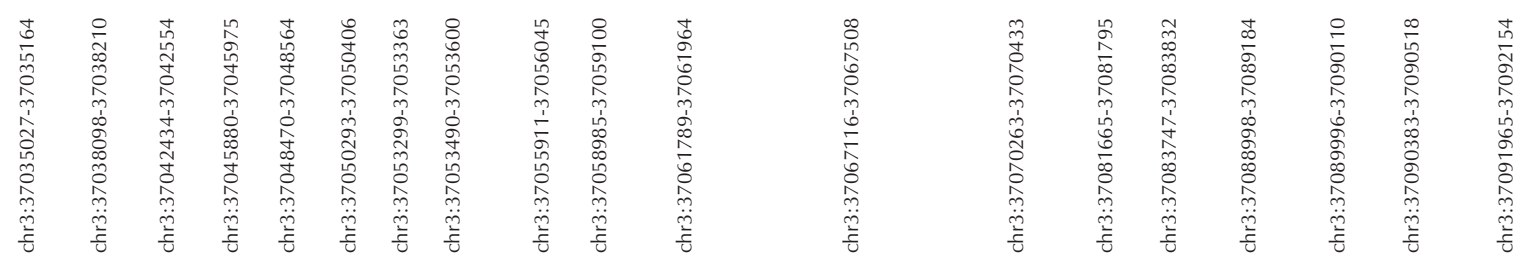
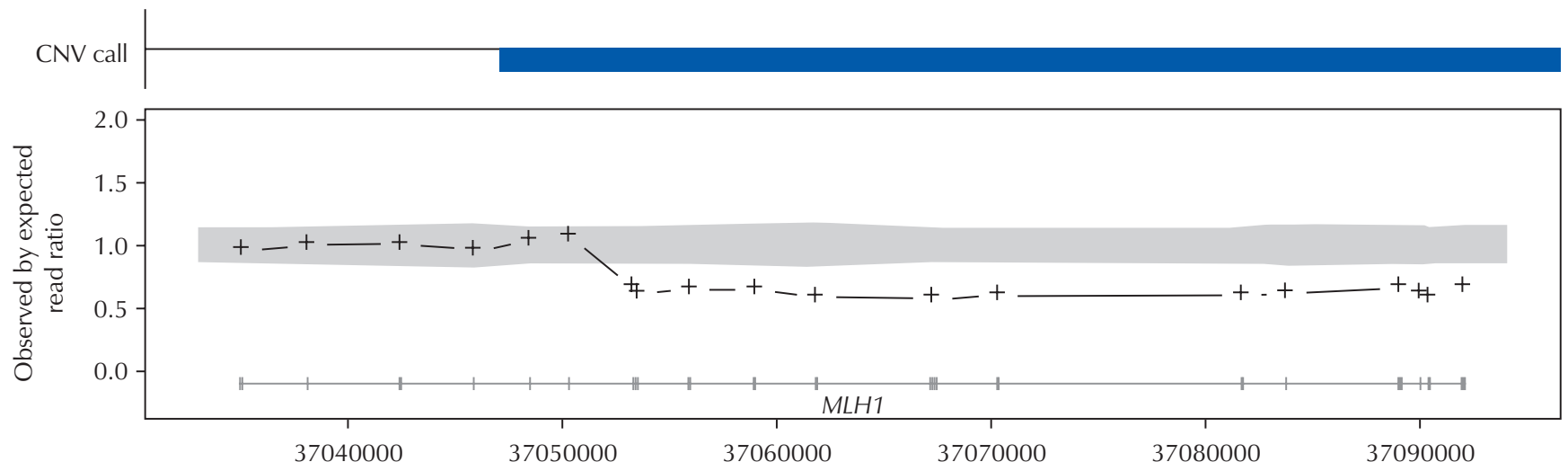

Fig. 1. Copy number loss of exon 7 to exon 19 of the MLH1 gene detected by next-generation sequencing. Abbreviation: CNV, copy number variation. 


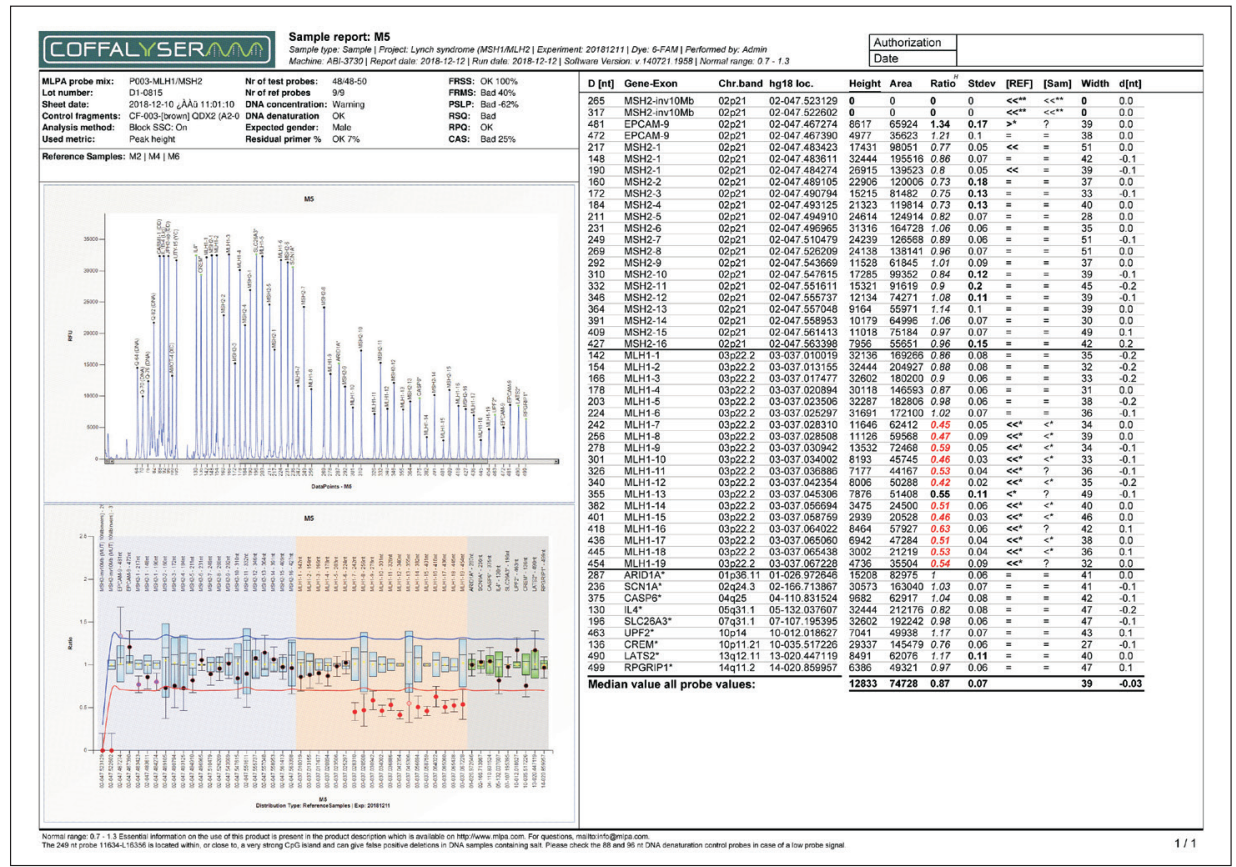

Fig. 2. Multiplex ligation-dependent probe amplification analysis of the MLH1 gene showing a deletion from exon 7 to exon 19.
한 종양 발생에 관여하는 128 개의 주요 유전자의 엑손 염기서 열 전체를 범위로 하는 맞춤 제작 패널로, NGS 패널검사결과, single nucleotide variant (SNV) 및 작은 크기의 삽입과 결 실을 검출하는 알고리즘에서는 pathogenic variant나 variant of uncertain significance는 발견되지 않았다. 그러나 readdepth 방식을 기반으로 한 copy number variation (CNV) 검출 알고리즘(DxSeq Gene Analysis System; Dxome, Seoul, Korea)상 3번 염색체의 37,053,286-37,092,169 범위, 즉 NM_000249 transcript 기준으로 MLH1 유전자의 엑손 7 부터 엑손 19 까지의 범위에서 normalized read depth ratio 가 0.62 로 결실이 의심되는 소견이 관찰되었다(Fig. 1). 확 인 검증을 위하여 MLH1 유전자에 대해 multiplex ligationdependent probe amplification (MLPA) 검사를 시행한 결과, NGS 패널검사결과와 동일하게 엑손 7 부터 엑손 19 까지의 결 실소견이 확인되었다(Fig. 2). 따라서 MLH1의 엑손 7-19 결 실 변이가 환자의 임상양상과 강한 연관성을 가지는 변이로 생 각되어, 환자 본인에 대한 능동적 감시 및 환자의 모친, 누나 및 추후 환자의 자녀에 대한 유전자검사를 권유하였다.

\section{고찰}

대장암 환자의 대부분은 가족력이 없는 경우가 많으나, 약 $15 \%-30 \%$ 의 환자들은 가족 구성원들 중에 대장암의 가족력이 관찰되며, 이는 가족성 대장암을 시사하는 소견이다[1]. 또한
대장암의 약 $5 \%$ 정도는 매우 발현성이 높은 유전성 변이와 관 련이 있다[2]. 유전성 대장암의 유전학에 대한 정확한 이해는 위험군 파악, 암 감시 및 예방전략의 개선, 향상된 진단적·치 료적 접근법의 개발을 위해 매우 중요하다[2].

유전성 대장암 중 가장 흔한 것은 Lynch syndrome으로, 주 로 대장암, 결장암 및 여성의 경우 자궁내막암의 위험을 증가 시킨다. Lynch syndrome은 DNA MMR gene의 결함이 유전 되는 상태로 현재 정립되어 있다. Lynch syndrome의 암 발생 경향성은 mutL homologue 1 (MLH1), mutS homologue 2 (MSH2), MSH6, 그리고 postmeiotic segregation increased 2 (PMS2)의 4개의 주요 DNA MMR gene의 상염색체 우성 이형접합 germline 변이에 의해 일어난다. 이 변이에 의해서 생성되는 단백질의 기능 상실이 일어나고, 남아 있는 야생형 대립유전자에 기능 상실 체세포 돌연변이가 일어나면서 $\mathrm{MMR}$ system에 결함이 일어나게 된다. 이로 인해 체성 유전자 결함 이 교정되지 않고 축적되면서 Lynch syndrome과 연관된 것 으로 알려진 암이 발생하게 된다. 이러한 종양들은 전형적으로 microsatellite repeat legion의 tandem repeat의 길이 변화인 MSI를 나타내게 된다[3]. Lynch syndrome의 진단에 대한 임 상지침에는 Amsterdam criteria와 Bethesda guidelines for testing of colorectal tumours for microsatellite instability [4]가 있으며, 본 증례의 환자는 Bethesda guideline에 해당 하여 Lynch syndrome으로 진단할 수 있었다.

Lynch syndrome의 평가는 임상적 표현형, 종양의 병리학 


\section{LABORATORY MEDICINE and QUALITY ASSURANCE}

Jinyoung Hong et al • A Case of MLH1 Exonic Deletion

적 소견과 유전적 스크리닝 검사를 통해 이루어진다. 현재 모 든 대장암 환자에게서 $\mathrm{MSI}$ 검사와 $\mathrm{MMR}$ 단백질의 결실을 감지하는 면역조직화학염색이 효율적이고 비용 효과적이라 는 근거가 많이 있다[3]. 면역조직화학염색을 통해 어떤 특정 $\mathrm{MMR}$ 유전자가 병적 변이를 가지고 있는지 유추할 수 있다. 그러나 Lynch syndrome의 정확한 원인 파악은 MMR 유전 자의 deleterious germline variant의 검출을 통해 가능하므 로 이를 감지해 내는 능력은 MSI-high, 면역조직화학염색 소 견 등에 의해 유전성 대장암이 의심되는 환자에게서 유전학검 사를 선택할 때 중요한 고려사항이다. 현재 Lynch syndrome 과 관련하여 stop codon을 만드는 nonsense 또는 frameshift variant, 아미노산의 치환을 일으키는 missense variant 등이 주요한 변이로 보고되어 있으나, 본 증례에서와 같이 $M L H 1$ 과 $\mathrm{MSH} 2$ 유전자에서 큰 크기의 엑손 단위의 결실 또한 보 고되고 있다. 임상적으로 Lynch syndrome의 양상을 보이며 MSI-high 소견을 보이는 환자의 많게는 $50 \%$ 까지에서 4 개의 주요 MMR 유전자의 변이를 검출해 내지 못한다는 보고가 있 다[5].

2019년 InSiGHT 데이터베이스 기준으로 위장관계 암 발생 에 기여하는 MMR 유전자의 likely pathogenic · pathogenic 유전자 변이는 $M L H 1$ 에서 2,868개, $M S H 2$ 에서 4,616개, MSH6에서 1,199개, 그리고 PMS2에서 518개가 보고되어 있 다[6]. MLH1, MSH2, MSH6, PMS2 유전자에 대한 전통적 인 Sanger sequencing은 SNV 및 적은 수의 염기 결실과 중복 을 검사할 수 있으나, 본 증례에서와 같이 $\mathrm{CNV}$ 로 나타나는 엑 손 하나 이상의 변화가 생기는 큰 크기의 결실과 중복은 검출 해낼 수 없는 한계점이 있다. 본 증례에서 확진검사법으로 사 용한 MLPA의 경우, 몇십-몇백 개의 염기서열을 표적으로 하 는 표지자를 사용하여 단일 엑손 단위의 결실과 중복을 확인하 기에 좋은 기법이나, 사용하는 표지자의 개수가 제한되어 있어 몇몇 특정한 경우에 사용이 용이하고 genome-wide screening 에는 적당하지 않다[7].

NGS를 이용한 CNV 검출은 paired-end mapping, split read, read depth, de novo assembly of a genome, 그리고 이 접근방식들의 조합의 크게 다섯 가지 전략을 통해 이루어 진다[8]. 이 중 본 증례에서 사용된 방식은 read depth 방식이 다. 이것은 기본적으로 만약 어떠한 유전자가 결실되거나 중 복되었다면, 그 유전자가 genome에 있는 다른 유전자에 비 해서 적거나 많은 copy 수를 가질 것이고, sequencing이 일 어났을 때 비율적으로 다른 유전자에 비해 적거나 많은 증폭 된 read 수를 가질 것이라는 원리를 기반으로 한다. 물론 다 른 thermocycler의 사용, 시약의 변화, 수기작업과 같은 외부
적 요인과 GC content 등의 내부적 요인에 의해서 read 수의 변화가 일어날 수 있기 때문에, $\mathrm{NGS}$ 를 통한 $\mathrm{CNV}$ 검출의 제 한점이 있을 수 있다[9]. 그러나 NGS는 Sanger sequencing 이나 MLPA와 달리 한 번의 검사로 많은 수의 유전자에 대해 $\mathrm{SNV}$ 와 CNV를 screening할 수 있어, 유전성 대장암을 포함한 여러 종양증후군에서 원인 유전자와 변이를 파악하기에 유용 한 검사법이다.

본 증례에서는 MLH1유전자의 7번 엑손에서 19 번 엑손 까지를 범위로 하는 크기가 큰 결실이 발견되었다. 이 변이 는 Human Gene Mutation Database (HGMD)에 등록되 지 않은 변이이나, HGMD에 등록된 1,237 개 변이 중 156 개 가 gross deletion으로, 본 증례와 같은 엑손 단위의 결실은 $M L H 1$ 유전자의 병적 변이의 $10 \%$ 이상을 차지하고 있다. 따 라서 MSI-high로 MMR gene의 변이가 의심되는 대장암 환자 에 대해 유전적 검사를 시행할 때, CNV를 검출할 수 있는 검 사법을 사용하지 않으면 상당수의 환자에서 이상소견을 놓쳐 확진을 어렵게 할 위험이 있다. 또한 한 연구에서 77 명의 임상 적으로 Lynch syndrome이 의심되며 종양 조직에서 $\mathrm{MSH} 2$ 단백질의 결실이 있었으나, MSH2 또는 MSH6의 변이가 발 견되지 않은 환자를 대상으로 genome 범위의 $\mathrm{CNV}$ 분석을 시 행하였을 때, 새로운 후보 유전자의 가능성이 있는 유전자들을 발견할 수 있었다는 보고가 있어[10], CNV 분석은 가족성 대 장 종양에 대한 유전적인 이해를 보다 넓히는 데 기여할 수 있 을 것으로 생각된다.

결론적으로, 종양 조직에 대한 MSI testing 또는 면역조직 화학염색 검사 등을 통해 유전성 대장암이 의심되는 환자에게 서 원인 파악을 위한 유전학검사를 시행할 때, 반드시 $\mathrm{CNV}$ 의 검출을 포함하는 검사법을 사용하여야 할 것이다. 이러한 관점 에서 현재 널리 시행되고 있는 NGS는 종양증후군을 일으키는 다수의 유전자에 대해 SNV와 CNV를 동시에 검사할 수 있는 임상적 타당성이 있는 검사법으로, 유전성 대장암 환자에게서 시행이 적극적으로 고려되어야 할 것이다.

\section{REFERENCES}

1. Mork ME, You YN, Ying J, Bannon SA, Lynch PM, Rodriguez-Bigas MA, et al. High prevalence of hereditary cancer syndromes in adolescents and young adults with colorectal cancer. J Clin Oncol 2015;33:3544-9.

2. Jasperson KW, Tuohy TM, Neklason DW, Burt RW. Hereditary and familial colon cancer. Gastroenterology 2010;138:2044-58. 


\section{LABORATORY MEDICINE and QUALITY ASSURANCE}

Jinyoung Hong et al • A Case of MLH1 Exonic Deletion

3. Lynch HT, Snyder CL, Shaw TG, Heinen CD, Hitchins MP. Milestones of Lynch syndrome: 1895-2015. Nat Rev Cancer 2015;15:181-94.

4. Umar A, Boland CR, Terdiman JP, Syngal S, de la Chapelle A, Ruschoff J, et al. Revised Bethesda guidelines for hereditary nonpolyposis colorectal cancer (Lynch syndrome) and microsatellite instability. J Natl Cancer Inst 2004;96:261-8.

5. Masson AL, Talseth-Palmer BA, Evans TJ, Grice DM, Duesing K, Hannan GN, et al. Copy number variation in hereditary non-polyposis colorectal cancer. Genes (Basel) 2013;4:536-55.

6. International Society for Gastrointestinal Hereditary Tumours. InSiGHT DNA Variant Database. https://www. insight-database.org/ (Accessed September 20, 2019).

7. Schouten JP, McElgunn CJ, Waaijer R, Zwijnenburg D,
Diepvens F, Pals G. Relative quantification of 40 nucleic acid sequences by multiplex ligation-dependent probe amplification. Nucleic Acids Res 2002;30:e57.

8. Zhao M, Wang Q, Wang Q, Jia P, Zhao Z. Computational tools for copy number variation (CNV) detection using next-generation sequencing data: features and perspectives. BMC Bioinformatics 2013;14 Suppl 11:S1.

9. Ellis J. Analyzing gene copy number variation with NGS. https://www.biocompare.com/Editorial-Articles/356650Analyzing-Gene-Copy-Number-Variation-with-NGS/ (Accessed September 20, 2019).

10. Kayser K, Degenhardt F, Holzapfel S, Horpaopan S, Peters $\mathrm{S}$, Spier I, et al. Copy number variation analysis and targeted NGS in 77 families with suspected Lynch syndrome reveals novel potential causative genes. Int J Cancer 2018; 143:2800-13. 